\title{
Comparison of duloxetine and SSRI as a treatment option of painful physical symptoms associated with major depressive disorder
}

This article was published in the following Dove Press journal:

Neuropsychiatric Disease and Treatment

3 October 2017

Number of times this article has been viewed

\section{Miqdad Haider'}

Muhammad Nabeel Shafqat ${ }^{2}$

'Department of Medicine, Fatima Memorial Hospital, Fatima Memorial College of Medicine and Dentistry, Lahore, Pakistan; ${ }^{2}$ Department of Medicine, University of Medical Sciences "Serafin Ruiz de Zarate" Villa Clara (UCMVC), Villa Clara, Cuba
Correspondence: Miqdad Haider Department of Medicine, Fatima Memorial Hospital, 725 Shadman Road, Lahore 54000, Pakistan

Email miqdadI4@yahoo.com

\section{Dear editor}

We would like to write about the recently published article "An observational study of duloxetine versus selective serotonin reuptake inhibitors (SSRIs) monotherapy for the treatment of painful physical symptoms in Japanese patients with major depressive disorder: primary analysis" by Kuga et al, which we read with great interest. ${ }^{1}$ The study is a good step toward finding the best treatment option for painful physical symptoms (PPSs) in patients with major depressive disorder (MDD).

Depression (MDD) is a type of mood disorder which affects individuals in such a way that they behave differently toward society. It causes abnormalities in the way of thinking, feeling, and handling daily activities of life. It is a common entity and its symptoms can be divided into two groups, namely physical (insomnia, lethargy, anorexia, PPSs) and psychological (guilt, feeling of worthlessness, agitation). ${ }^{2}$ In a cross-sectional study performed on individuals from different European countries, $50 \%$ of patients with MDD had experienced PPS as compared to normal population, where $29 \%$ of respondents reported PPS. It concluded that certain risk factors like female gender, age, and lower educational level were more likely to cause PPS. ${ }^{3}$

PPSs include pain in joints and stomach, headache, myalgia, and backache. Serotonin and norepinephrine both have a role in the pathogenesis of PPS and MDD which explains their association. There is a study ${ }^{4}$ which showed that treatment of PPS helps in control of emotional symptoms. This suggests that the patient's capacity to achieve depression remission has a direct relation with the reduction of PPS. A treatment plan which ignores physical symptoms may result in failure of remission and can also lead to poor prognosis. Commonly used treatment options for PPS are SSRIs (fluoxetine) and serotonin-norepinephrine reuptake inhibitor (SNRI; duloxetine).

In this observational study, which claims to be the first study to compare duloxetine and SSRIs, the researchers have tried to find the best treatment option for PPS symptoms in patients with MDD. After 4 weeks, the difference in average pain score between the two groups was not substantial; however, there was an improvement in patients on duloxetine after 4-12 weeks. No serious adverse effects were reported. These results lead to the conclusion that duloxetine is promising and showed significant improvement in PPS compared to SSRIs.

If we review some previous studies which compared these two drug groups, we have different results. A study "Depression and pain: an appraisal of cost-effectiveness and cost utility of antidepressants" by Yan et al concluded that SSRIs have an edge 
over duloxetine (an SNRI) for MDD patients with PPS keeping in view the cost utility and cost-effectiveness. ${ }^{5}$ Another study concluded that when PSS patients partially responding to SSRI were switched to duloxetine, there was a significant improvement in pain regardless of the switch method used. ${ }^{6}$

We suggest that similar studies are carried out in other parts of the world involving multiethnic population as results can be influenced by race/cultural differences. There is a need for further randomized studies to support the use of duloxetine over SSRIs in MDD patients with PPS.

\section{Disclosure}

The authors report no conflicts of interest in this communication.

\section{References}

1. Kuga A, Tsuji T, Hayashi S, et al. An observational study of duloxetine versus SSRI monotherapy for the treatment of painful physical symptoms in Japanese patients with major depressive disorder: primary analysis. Neuropsychiatr Dis Treat. 2017;13:2105.
2. Ang QQ, Wing YK, He Y, et al. Association between painful physical symptoms and clinical outcomes in East Asian patients with major depressive disorder: a 3-month prospective observational study. Int $J$ Clin Pract. 2009;63(7):1041-1049.

3. Denninger JW, Mahal Y, Merens W, et al. The relationship between somatic symptoms and depression. In New Research Abstracts of the 155th annual meeting of the American Psychiatric Association; 2002 May 21 (Vol. 21).

4. Harada E, Tokuoka H, Fujikoshi S, et al. Is duloxetine's effect on painful physical symptoms in depression an indirect result of improvement of depressive symptoms? Pooled analyses of three randomized controlled trials. Pain. 2016;157(3):577.

5. Pan YJ, Pan CH, Chan HY, Kuo KH. Depression and pain: an appraisal of cost effectiveness and cost utility of antidepressants. J Psychiatr Res. 2015;63:123-131.

6. Perahia DG, Quail D, Desaiah D, Montejo AL, Schatzberg AF. Switching to duloxetine in selective serotonin reuptake inhibitor non-and partialresponders: effects on painful physical symptoms of depression. J Psychiatr Res. 2009;43(5):512-518. 


\section{Authors' reply}

Atsushi Kuga'

Toshinaga Tsuji ${ }^{2}$

Shinji Hayashi

Mako Matsubara ${ }^{3}$

Shinji Fujikoshi ${ }^{4}$

Hirofumi Tokuoka'

Aki Yoshikawa $^{5}$

Rodrigo Escobar 6

Kazuhide Tanaka ${ }^{7}$

Takaharu Azekawa $^{8}$

'Bio Medicine, Medicines Development Unit Japan, Eli Lilly Japan K.K., Kobe, ${ }^{2}$ Medical Affairs Department, ${ }^{3}$ Pharmacovigilance Department, Shionogi \& Co. Ltd, Osaka, ${ }^{4}$ Statistical Science, ${ }^{5}$ Scientific Communications, Medicines Development Unit Japan, Eli Lilly Japan K.K., Kobe, Japan; ${ }^{6}$ Bio-Medicines, Eli Lilly and Company, Indianapolis, IN, USA; ${ }^{7}$ Hitsuji Clinic, Kusatsu, Japan; ${ }^{8}$ Shioiri Mental Clinic, Yokosuka, Japan

Correspondence: Atsushi Kuga

Bio Medicine, Eli Lilly Japan K.K., I-7-5 Isogamidori, Chuo-ku, Kobe,

Hyogo, 65I-0086, Japan

Tel +8I 782424579

Fax +8I 782429939

Email kuga atsushi@lilly.com

\section{Dear editor}

We appreciate Drs Haider and Shafqat's close reading of our manuscript. As they mentioned, the noradrenergic action of serotonin-norepinephrine reuptake inhibitors (SNRIs) on descending pain modulation pathways may explain its advantageous effect on painful physical symptoms (PPSs) in patients with major depressive disorder (MDD). ${ }^{1}$ In reference to the report by our colleagues regarding the effect of duloxetine on PPS in MDD, ${ }^{2}$ they stated that any treatment plan for depression that ignores physical symptoms may lead to failure of remission and poor prognosis. Harada et $\mathrm{al}^{2}$ in their report were very much aware of this and showed that initially the direct effect of duloxetine on PPS associated with MDD was greater than its indirect effect, whereas later the indirect effect through improvement in depressive symptoms predominated. In our study, ${ }^{3}$ we were concerned with showing how to optimize the treatment of MDD with PPS. This clinical question led us to plan our study comparing duloxetine and selective serotonin reuptake inhibitors (SSRIs). ${ }^{3,4}$

After commenting on our study results, Drs Haider and Shafqat referred to two studies that appeared to have different results. First, the study by Pan et $\mathrm{al}^{5}$ demonstrated the superior cost-effectiveness of SSRIs over SNRIs in terms of depression and pain in Taiwan. However, it is unclear which treatment the patients in the SNRI group received, duloxetine or venlafaxine. Moreover, this was a retrospective study based on drug prescription data, and careful assessment of clinical information (ie, severity of depression and pain, dosage of each antidepressant, etc) was not in scope. Those limitations should be taken into account for appropriate interpretations.

On the other hand, the study by Perahia et $\mathrm{al}^{6}$ found significant improvements in PPS in MDD patients responding to SSRIs after switching to duloxetine irrespective of switching methods. This study supports usefulness of duloxetine in treating PPS as an alternative to SSRI. With that said, we would like readers to note that their study population was different from our study and their study was not designed to compare the antidepressants before and after switching. In addition, they used change in HAM-D scores as the primary objective, not pain improvement.

In order to resolve these differences, we wanted to examine pain improvement in MDD patients as the primary objective in this observational study. This is the first study, and we hope that our data may stimulate to further investigations that lead toward optimal treatment of MDD with PPS.

\section{Disclosure}

AK, SF, HT, AY, and RE are employees of Eli Lilly Japan K.K. TT, SH, and MM are full-time employees and stockholders of Shionogi \& Co., Ltd. KT has no disclosures. TA received speakers' honoraria from Eli Lilly Japan, K.K., Takeda Pharmaceutical Co. Ltd., Otsuka Pharmaceutical Co. Ltd., Mochida Pharmaceutical Co., Ltd., and Janssen Pharmaceutical K.K.

\section{References}

1. Kwon M, Altin M, Duenas H, Alev L. The role of descending inhibitory pathways on chronic pain modulation and clinical implications. Pain Pract. 2014;14(7):656-667.

2. Harada E, Tokuoka H, Fujikoshi S, et al. Is duloxetine's effect on painful physical symptoms in depression an indirect result of improvement of depressive symptoms? Pooled analyses of three randomized controlled trials. Pain. 2016;157(3):577-584.

3. Kuga A, Tsuji T, Hayashi S, et al. An observational study of duloxetine versus SSRI monotherapy for the treatment of painful physical symptoms in Japanese patients with major depressive disorder: primary analysis. Neuropsychiatr Dis Treat. 2017;13:2105-2114.

4. Kuga A, Tsuji T, Hayashi S, et al. An observational study of duloxetine versus SSRI monotherapy in Japanese patients with major depressive disorder: subgroup analyses of treatment effectiveness for pain, depressive symptoms, and quality of life. Neuropsychiatr Dis Treat. 2017;13: 2115-2124.

5. Pan YJ, Pan CH, Chan HY, Kuo KH. Depression and pain: an appraisal of cost effectiveness and cost utility of antidepressants. J Psychiatr Res. 2015;63:123-131.

6. Perahia DG, Quail D, Desaiah D, Montejo AL, Schatzberg AF. Switching to duloxetine in selective serotonin reuptake inhibitor non- and partialresponders: effects on painful physical symptoms of depression. J Psychiatr Res. 2009;43(5):512-518. 
Dove Medical Press encourages responsible, free and frank academic debate. The content of the Neuropsychiatric Disease and Treatment 'letters to the editor' section does not necessarily represent the views of Dove Medical Press, its officers, agents, employees, related entities or the Neuropsychiatric Disease and Treatment editors. While all reasonable steps have been taken to confirm the content of each letter, Dove Medical Press accepts no liability in respect of the content of any letter, nor is it responsible for the content and accuracy of any letter to the editor.

Neuropsychiatric Disease and Treatment

Dovepress

\section{Publish your work in this journal}

Neuropsychiatric Disease and Treatment is an international, peerreviewed journal of clinical therapeutics and pharmacology focusing on concise rapid reporting of clinical or pre-clinical studies on a range of neuropsychiatric and neurological disorders. This journal is indexed on PubMed Central, the 'PsycINFO' database and CAS,

and is the official journal of The International Neuropsychiatric Association (INA). The manuscript management system is completely online and includes a very quick and fair peer-review system, which is all easy to use. Visit http://www.dovepress.com/testimonials.php to read real quotes from published authors.

Submit your manuscript here: http://www.dovepress.com/neuropsychiatric-disease-and-treatment-journal 